\title{
SISTEMA DE PREVENÇÃO INTELIGENTE CONTRA INCÊNDIOS E GASES INFLAMÁVEIS EM AMBIENTES FECHADOS
}

Sandy Alice de Siqueira Arcoverde (UFCG) sandyalice13@gmail.com

Jordan Matheus Barbosa Araújo (UFCG) jordan_barbosa517@ hotmail.com

Marcos Vinicius Mendes de Carvalho (UFCG) marcosviniciosmendes@gmail.com

Erik Tavares Galdino (UFCG) ErikTavares87@gmail.com

Jefferson Teixeira de Souza (UFCG) jefferson97ufcg@gmail.com

\section{Resumo}

Com o passar dos anos, pudemos observar fatos tristes envolvendo ambientes fechados e intoxicação por gases. Um caso não tão recente, porém famoso desse tipo de acontecimento, foi o incêndio na boate Kiss em meados de 2013. Para evitar novos acidentes como este, foi desenvolvido esse projeto que tem o objetivo desenvolver um sistema de prevenção inteligente contra incêndios e gases inflamáveis em ambientes fechados, que funcionará da seguinte forma: O sistema monitora a quantidade de gás inflamável ou fumaça no local através do sensor MQ-2 e em caso de quantidades que possa ocasionar algum risco, aciona o alarme e aciona os exautores para a retirada do gás e fumaça para o ambiente externo, evitando incêndios e a intoxicação das pessoas. Sistemas inteligentes como esses podem ser utilizados em casas comuns, boates e estabelecimentos no geral. Outro quesito importante do sistema é o custo final extremamente reduzido para implementação tendo em vista a proteção que o sistema oferece as pessoas do local.

Palavras-Chaves: Fumaça, intoxicação, gases, sistemas inteligentes.

\section{Introdução}

Vazamentos de gases tóxicos, inclusive $\mathrm{CO} 2$, não são tão frequentes quanto acidentes automobilísticos, por exemplo. Porém, são tão ou até mais perigosos. Quando algum vazamento de gás ou incêndio é notificado pela mídia, em caso de uma casa, por exemplo, é quase certeza que exista pelo menos uma pessoa intoxicada ou, em casos extremos, até morte por sufocação.

Geralmente, nas casas comuns, não existem dispositivos que auxiliem a controlar e destina gases prejudiciais aos membros das famílias, tampouco, extintores de incêndio, que agrava ainda mais as condições de risco de famílias de todo o Brasil, ainda mais porque grande parte 
das famílias não sabem se portar em casos de incêndio, por exemplo, quando um bujão de gás vaza ou algum móvel de tecido começa a pegar fogo. Bombeiros sempre fazem tutoriais como se portar em situações como estas, porém, mesmo assim, a população não tem conhecimento próprio para se portar ou se acalmar em ocasiões complicadas.

Em edifícios no geral, a rigorosidade com esses riscos se eleva e a presença de extintores se torna obrigatória graças à normas previstas na NR-23 que tratam de incêndios, porém a manutenção e troca de extintores invalidados se torna obsoleta, pois os síndicos e responsáveis pelas manutenções dos extintores nem sempre fazem tais mudanças necessárias. Já na industrial, essa preocupação apenas cresce, no sentido de que as empresas estão se preocupando com o bem-estar e a saúde dos trabalhadores.

Diante dessa crescente preocupação por parte das empresas, segundo os dados do Observatório Digital de Saúde e Segurança do Trabalhador, acidentes por inalações de gases, poeiras e vapores caíram consideravelmente entre 2012 e 2017, de 77.312 para 57.490, cerca de 25,6\%. As mortes também tiveram um abatimento de 138 para 90, com um percentual de $34,8 \%$.

Em meados de 2019, uma família composta por 6 pessoas foi morta por intoxicação pelo gás monóxido de carbono, segundo matéria do Uol, oriundo do sistema de aquecimento do prédio e tenha chegado ao apartamento pelo chuveiro do prédio. Mortes por inalação de gases no Brasil tenderam a crescer.

Figura 1- Mortes por intoxicação acidental por gases e vapores
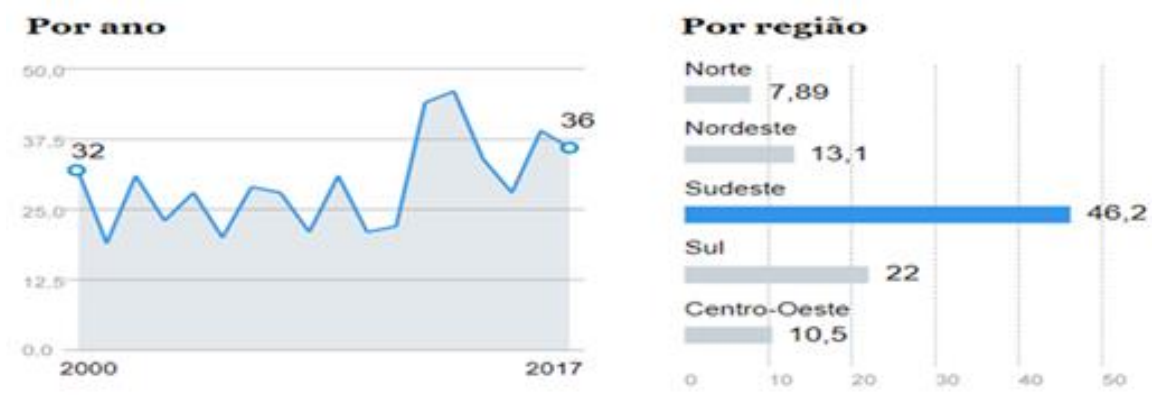

Fonte: Datasus (2019)

Como visto na figura, a região Sudeste lidera o número de mortes com gases tóxicos no Brasil. O caso mais conhecido, foi o incêndio e liberação de gases tóxicos na boate Kiss no dia 27 de janeiro de 2013, onde um show de pirotecnia iniciou um incêndio por conta de que 
os fogos atingiram uma espuma que liberou gases, e os mesmos intoxicaram as pessoas do local. Nisso, 242 pessoas morreram e 608 ficaram feridas.

Em escala mundial, recentemente, o incêndio mais famoso e triste foi o que aconteceu no Museu do Louvre, na França, onde resultou em uma perda material e cultural enorme à população.

Por mais que grande parte das residências não tenham nenhum tipo de sistema que combata fogo, fumaça e/ou gases tóxicos, a procura por sistemas inteligentes vem crescendo nos últimos anos, segundo a ABESE (Associação Brasileira das Empresas de Sistemas Eletrônicos de Segurança), cada vez mais as pessoas estão procurando dispositivos que operem de maneira preventiva.

Sabendo disso, esse projeto tem como objetivo desenvolver um sistema de prevenção inteligente contra incêndios e gases inflamáveis em ambientes fechados, o sistema monitora a quantidade de gás inflamável ou fumaça no local através do sensor MQ-2 e em caso de quantidades que possa ocasionar algum risco, aciona o alarme e aciona os exautores para a retirada do gás e fumaça para o ambiente externo o mais rápido possível, evitando acidentes e salvando vidas.

\section{Referencial Teórico}

\subsection{Nr-23}

Dentro do ambiente profissional, os operários estão expostos a doenças e riscos físicos, químicos, biológicos, ergonômicos e de acidentes.

Em contraponto, existe a área de segurança do trabalho, que visa praticar medidas que mirem a diminuição dos incidentes no exercício da profissão, enfermidades ocupacionais e também a assegurar a integridade do trabalhador (MARTINS et al., 2010).

Com a criação de um grupo de NR's criadas em 1978, encontra-se a NR 23- Proteção Contra Incêndios. Desde 1978, quando foi criada, ela passou por várias mudanças e atualizações, com a finalidade de torna-se cada vez mais eficiente. Na composição atual da norma, ela retrata pôr na responsabilidade dos empregadores, "a adoção de medidas de prevenção de incêndios, em conformidade com a legislação estadual e as normas técnicas aplicáveis" (BRASIL, 2011). 
Na própria NR, é dito o que se compete ao patrão informar aos seus trabalhadores em respeito aos equipamentos de proteção e medidas protetivas em casos de incêndio, no caso, evacuações dos postos de trabalho com segurança e êxito, graças aos informes dos dispositivos de alarme que existem nas instalações dos postos de trabalho (BRASIL, 2011).

Para Seito et al. (2008), talvez pelo o motivo de ser uma área complicada para o conhecimento humano, a segurança contra incêndios tenha sido deixada para segundo plano em relação aos avanços das cidades, o que causa pouco material de estudo nacional sobre a área.

Em efeito, o conhecimento no Brasil se torna obsoleto justamente por apenas acompanhar acontecimentos do passado. Para Porto (2011), as leis técnicas e dispositivos que regem imposições mínimas de precauções de incêndios em edifícios e áreas de risco no Brasil são recentes, ocorrendo o que passou a ser tratado com maior importância a partir das duas grandes tragédias, que são: Andraus e Joelma. Recentemente, houve o caso do centro de treinamento do Clube de Regatas do Flamengo onde se resultou no total de 10 mortes, querendo ou não, mais um episódio triste para o Brasil.

\subsection{Inalação de monóxido de carbono}

De imediato, após um ser humano inalar algum gás tóxico, em especial o monóxido de carbono conhecido como CO, segundo Gerald F. O’Malley, os graus da inalação são divididos em 3: Intoxicação leve, intoxicação moderada e intoxicação grave.

- Intoxicação leve: Dor de cabeça, enjoo, tontura e vômitos;

- Intoxicação moderada: Falta de discernimento, confusão, inconsciência e convulsões;

- Intoxicação grave: Em grandes partes dos casos é fatal, quando não: Perda de memória, distúrbios de locomoção, depressão e psicose.

Geralmente, a intoxicação é feita pelas vias respiratórias, tendo em vista que o gás agride os pulmões, fazendo que o indivíduo seja asfixiado, podendo levar à morte em casos graves. Isso se dá, pois, a molécula de monóxido de carbono tem 200 vezes mais afinidade com a hemoglobina do que o oxigênio, fazendo com que diminua a quantidade de hemoglobina disponível para transporte entre as células do corpo. 


\section{Materiais}

No projeto foi utilizado o Arduino UNO, um Sensor de gases inflamáveis MQ-2, um Protoboard 830 pontos, um Jumpers macho-macho e macho-femea, um Relé 1 canal 5v, um Cooler $9 \mathrm{v}$ genérico e uma fonte de carregador $5 \mathrm{v}$.

Para o desenvolvimento desse projeto foi necessário ter conhecimento teórico sobre o tema e também sobre os componentes usados e dos softwares de programação.

Figura 2 - Monóxido de carbono

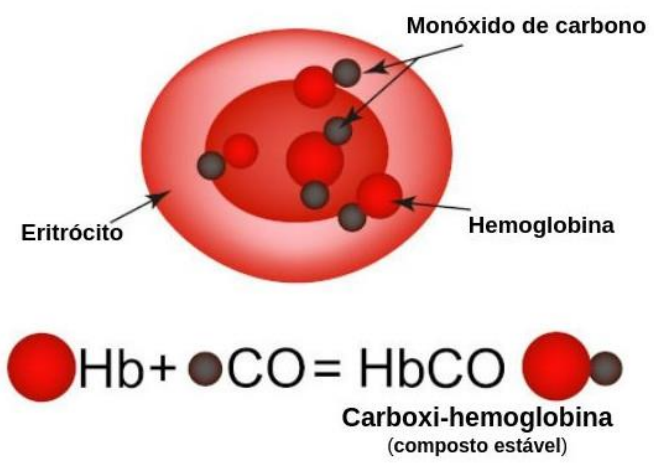

Fonte: FERREIRA, Victor Ricardo. "Monóxido de carbono"; Brasil Escola

O diagnóstico é dado de maneira simples, através de um exame sanguíneo, levando em consideração apenas a dosagem da concentração de monóxido de carbono no sangue.

O tratamento, por sua vez, é um processo natural ou complexo, dependendo da gravidade da situação ou das condições naturais do ser humano, por exemplo, se ele for fumante ou não. As medidas são:

- Ar fresco, em intoxicações mais leves;

- Oxigênio suplementar, em casos moderados;

- Técnica do oxigênio hiperbárico, em casos críticos.

\subsection{Arduino}

O Arduino é um dispositivo baseado em hardware livre, que possibilita melhora-lo, modificalo e personalizá-lo, partindo do hardware básico. Ele é acessível, funcional e fácil de programar. Ele foi criado por um grupo de 5 pesquisadores: Massimo Banzi, David Cuartielles, Tom Igoe, Gianluca Martino e David Mellis, em 2005. 
Dessa forma, eles desenvolveram uma placa composta por um microcontrolador Atmel, circuitos de entrada/saída e que pode ser facilmente conectada à um computador e programada via IDE (Integrated Development Environment, ou Ambiente de Desenvolvimento Integrado) utilizando uma linguagem baseada em $\mathrm{C} / \mathrm{C}++$. (filipeflop/blog/oque-e-arduino).

\section{Figura 3 - Microcontrolodor Arduino Uno}

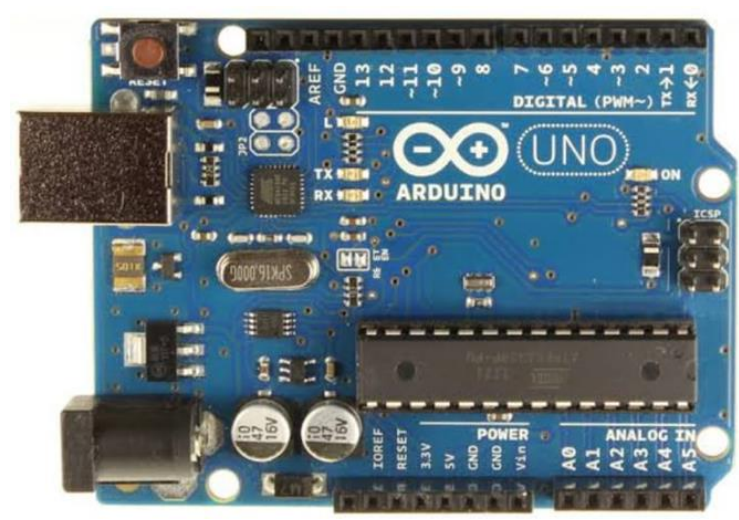

Fonte: Eletrodex (2019)

O micro controlador é um dispositivo semicondutor em forma de circuito integrado, que integra as partes básicas de um microcomputador - microprocessador, memórias não-voláteis e voláteis e portas de entrada e saída. Geralmente, é limitado em termos de quantidade de memória, principalmente no que diz respeito à memória de dados, é utilizada em aplicações específicas, ou seja, naquelas que não necessitam armazenar grandes quantidades de dados. Apresenta um custo bastante baixo e possui vários fornecedores. (GIMENEZ, 2002, p.4).

Foi utilizado neste projeto o micro controlador Arduíno UNO, por ter um fácil acesso no comércio, baixo custo, por suprir as necessidades do projeto e por ter uma linguagem de programação padrão conhecida por nós. O micro controlador Arduino consiste em uma placa de controle com entradas e saídas, com um cristal oscilador de $16 \mathrm{MHz}$, um regulador de tensão, plugue de alimentação, pinos conectores, LEDS para indicar modo de funcionamento de gravação, regulador de tensão de $05 \mathrm{~V}$ e uma porta USB.

\subsection{Sensor detector de fumaça e gases inflamáveis}

O sensor de gases inflamáveis é um módulo eletrônico desenvolvido com a finalidade de detectar a presença de gás inflamável / fumaça em determinado ambiente. A partir da detecção feita pelo sensor, ele emite uma saída, que normalmente é um sinal que será 
interpretado e convertido por outros dispositivos, ou seja, o sinal pode ser lido por um processador ou ser transmitido por uma rede de dados.

\section{Figura 4 - Microcontrolodor Arduino Uno}

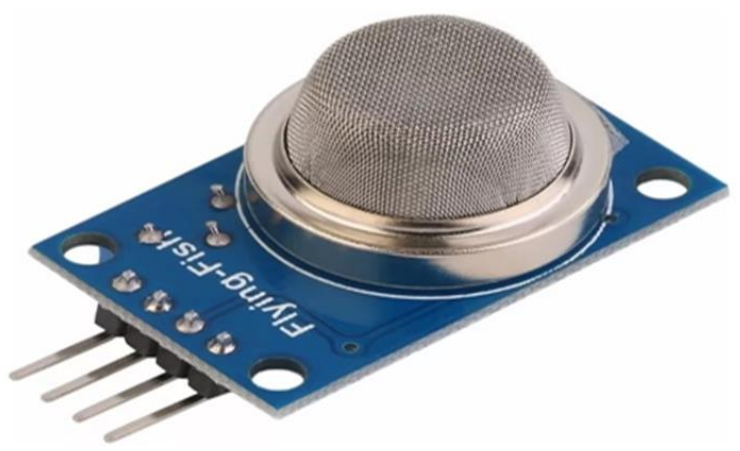

Fonte: Mercado livre (2019)

O sensor utilizado para detectar o vazamento de gás é o MQ-2 que apresenta as seguintes características:

- Modelo: MQ-2;

- Detecção de gases inflamáveis: GLP, Metano, Propano, Butano;

- Hidrogênio, Álcool, Gás Natural e outros inflamáveis;

- Detecção de fumaça;

- Concentração de detecção: 300-10.000ppm;

- Tensão de operação: 5V;

- Sensibilidade ajustável via potenciômetro;

- Saída Digital e Analógica;

- Fácil instalação;

- Comparador LM393;

- Led indicador para tensão;

- Led indicador para saída digital;

- Dimensões: 32 x 20 x $15 \mathrm{~mm}$. 


\subsection{Relé}

O relé tem um funcionamento bem simples, que quando uma corrente circula pela bobina, esta cria um campo magnético que atrai um ou uma série de contatos fechando ou abrindo circuitos e ao cessar a corrente da bobina o campo magnético também cessa, fazendo com que os contatos voltem para a posição original. Os relés podem ter diversas configurações quanto aos seus contatos: podem ter contatos NA, NF ou ambos, neste caso com um contato comum ou central (C). Os contatos NA (normalmente aberto) são os que estão abertos enquanto a bobina não está energizada e que fecham, quando a bobina recebe corrente. Os NF (normalmente fechado) abrem-se quando a bobina recebe corrente, ao contrário dos NA. O contato central ou $\mathrm{C}$ é o comum, ou seja, quando o contato NA fecha é com o $\mathrm{C}$ que se estabelece a condução e o contrário com o NF. (infoescola/eletrônica/relé).

\section{Figura 5 - Relé}

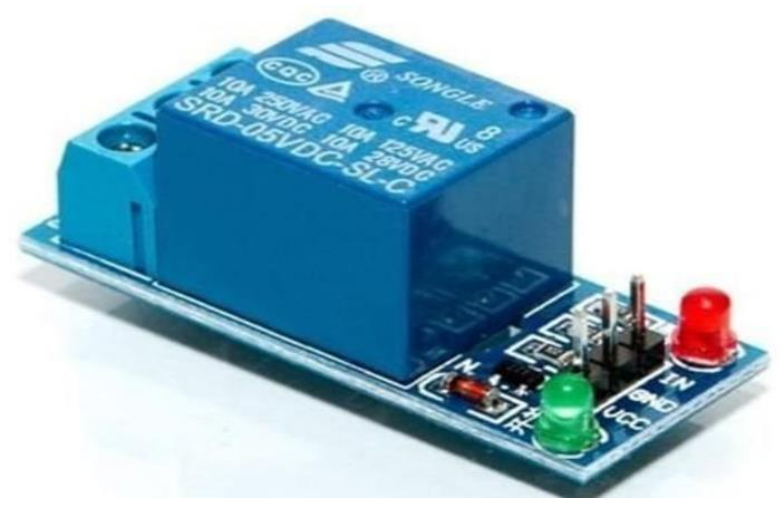

Fonte: Autocore Robótica (2019)

\subsection{Cooler}

O cooler serve para diminuir o calor gerado pelos componentes da máquina e principalmente o produzido pelo processador.

Os coolers usados no projeto foram os do modelo $9 \mathrm{v}$ genérico, para simular os nossos exaustores.

Em relação ao projeto, os coolers vão se associar a percepção de ambientes fechados mediante a pouca circulação do ar. Esses ambientes fechados podem ser tomados por gás e fumaça durante poucos minutos. 


\section{Figura 6 - Cooler}

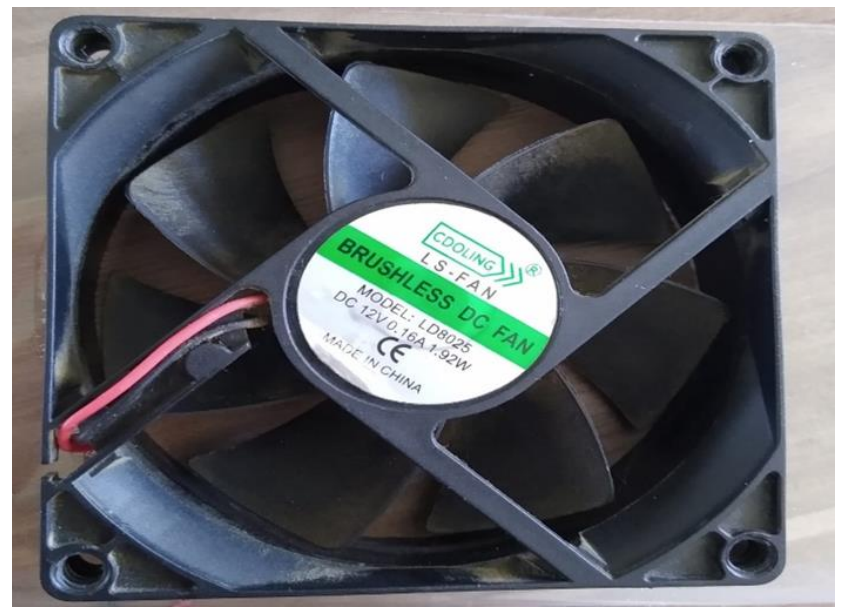

Fonte: Arquivo pessoal (2019)

\section{Metodologia}

O desenvolvimento deste sistema se deu por conta dos elevados casos de incêndio e intoxicação por gases inflamáveis que terminam de maneira trágica para várias pessoas e recordações culturais. Também pela falta de conhecimento necessário às pessoas de como se portar em casos de vazamentos de gases tóxicos e inflamáveis.

A priori, o primeiro passo do desenvolvimento do sistema foi realizar pesquisas sobre as NR's 23 (proteção contra incêndios) em revistas das áreas, artigos científicos, jornais, entre outros. Após tais pesquisas, deu-se início à elaboração de um artigo científico nas áreas apresentadas onde se pôde apresentar melhorias em sistemas já feitos antes acrescentando poucos custos, porém melhorando o desempenho do sistema.

Após tais pesquisas e parâmetros estabelecidos sobre o que se fazer, o material que seria utilizado foi definido, que são eles:

- Minicontrolador Arduino UNO;

- 1x protoboard de 830

- 1x sensor MQ-2;

- 1x buzzer;

- 1x led vermelho;

- 14x fios/jumpers; 
- 2x coolers;

- $1 \mathrm{x}$ relê;

- $1 X$ caixa de acrílico.

Figura 7 - Versão simplificada do sistema

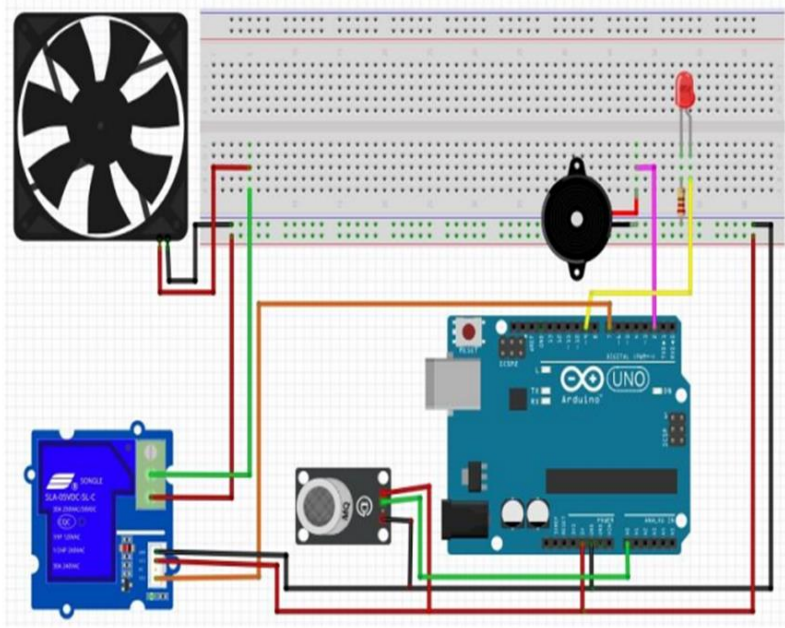

Fonte: Correia, Lima e Santos (2019)

Posteriormente, a montagem do circuito, a programação do Arduino foi feita para que, assim, o sensor ao detectar o mínimo sinal de gás, após menos de 1 segundo, em conjunto, os coolers, buzzer e led se acionem. Os coolers para retirar o gás do interior da caixa de acrílico simulando exaustores, o buzzer simulando sirenes para informar as pessoas que existe um gás periculoso no interior do ambiente, o led, funcionando como luzes de emergência que se pode indicar a saída do ambiente como medida de segurança. Mediante isso, após o sensor parar de detectar o gás, o cooler ainda permanece acionado após 3 segundos para garantir que todo o gás saia do ambiente. Tal diferença de tempo entre o "start" e o "finish" do sistema acionado é justamente para garantir que o ambiente fique o menor tempo possível com o gás e garantir que o gás saiu por completo. 
Figura 8 - Circuito Montado

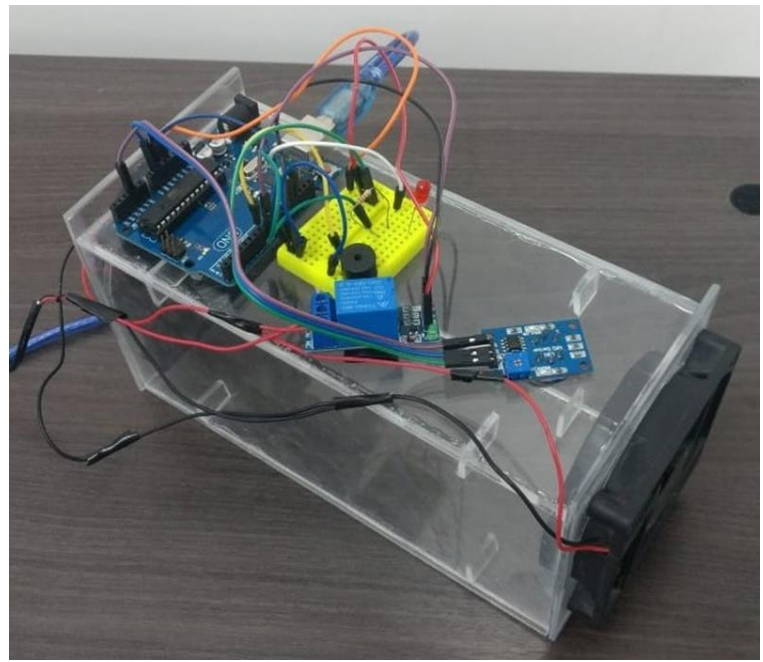

Fonte: Autores (2019)

O teste de funcionamento do sistema consistiu de forma manual através dos espaços das hélices (que são os únicos espaços que dão acesso ao interior da caixa, pois todo o ambiente é vedado com cola de isopor). Nisso, foi acionado uma lata de gás de isqueiro. Após isso, o ambiente fechado já tem uma alta concentração de gás, logo fazendo com que o sistema se acione.

Acima da caixa, o led irá ligar e o buzzer irá emitir um som, ambos informando que existe uma concentração de gás na caixa. Simultaneamente, os dois coolers irão estar em funcionamento para livrar o espaço do gás inflamável. Tal processo foi repetido outras vezes para verificar se existe alguma falha no sistema, porém isso não ocorreu.

Figura 9 - Introdução do gás na caixa

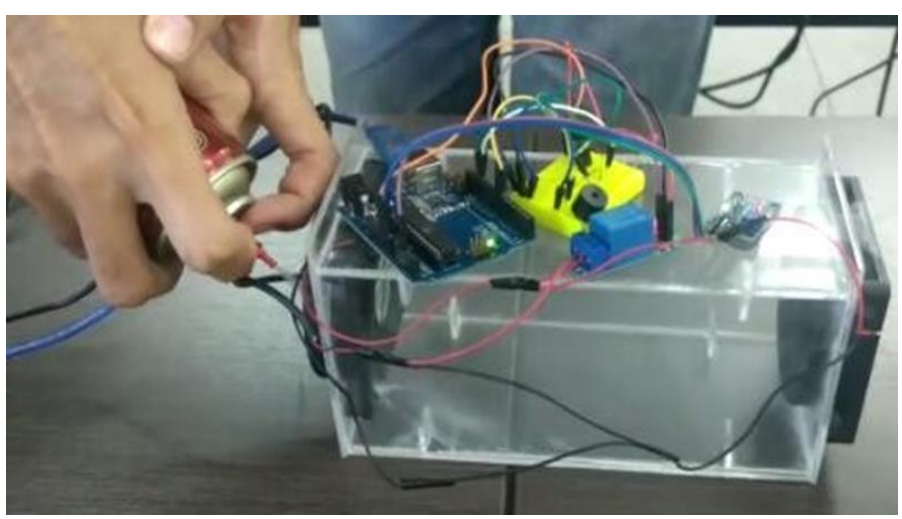

Fonte: Autores (2019) 


\section{Resultados}

Os resultados do experimento foram mais que satisfatórios, o sistema funcionou rapidamente, eliminando o gás inflamável do ambiente rapidamente.

Para o teste, foi utilizado um enlatado de gás de isqueiro que é composto de gás butano e gás propano (H3C-CH2-CH2-CH3 e $\mathrm{HC} 3-\mathrm{CH} 2-\mathrm{CH} 3$, respectivamente). Além de aerossol encontrado dentro da lata do gás.

\section{Considerações finais}

Foi criado neste trabalho um dispositivo que detecta vazamento de gás e fumaça, com a finalidade de trazer mais segurança com medidas de proteção. Conforme foi realizado os testes, o projeto teve resultados positivos, sendo assim pode ser utilizado para o devido fim, detecção de gás e fumaça em ambientes fechados.

Após feita as análises vimos que a participação do cooler e do sensor se mostraram bastante satisfatório devido ao seu rápido acionamento e a rápida detecção quando houve o acumulo de fumaça e gases inflamáveis.

O Arduino UNO utilizado, foi de extrema importância para a realização do projeto, pois através dele foi processado todo o sistema, além de ser um micro controlador fácil de programar.

O sistema apresentou bons resultados durante os testes realizados, mesmo em diferentes situações, já que o incêndio pode ser ocasionado por diversas causas.

O projeto é viável, pois os componentes são encontrados facilmente, com preços acessíveis, ou seja, o protótipo foi de baixo custo, além de proporcionar segurança e ter uma boa aceitação.

O projeto tem como missão uma sentinela 24 horas, monitorando o ambiente onde o sistema foi instalado, alertando quando houver um avento anormal que indique a presença de gases inflamáveis e de fumaça e agindo de forma automatizada.

O objetivo do projeto foi atingido, o protótipo funciona como planejado. O micro controlador atendeu a todas as funções do protótipo, que ainda pode ser melhorado sendo acrescido de outros componentes visando ideias futuras, que irão proporcionar mais segurança, evitando acidentes e, por conseguinte, salvando possíveis vítimas. 


\section{REFERÊNCIAS}

BRASIL, Ministério do Trabalho e Emprego. Norma Regulamentadora 23: Proteção Contra Incêndios. Diário Oficial da União República Federativa do Brasil, Brasília, DF, 10 mai. 2011. Disponível em: <http://trabalho.gov.br/images/Documentos/SST/NR/NR23.pdf>. Acesso em: 18 nov. 2019.

Brasil registra redução de acidentes de trabalho por agentes químicos. fispvirtual.com.br, 2018. Disponível em: <https://www.fispvirtual.com.br/16/2018/09/28/brasil-registra-reducao-de-acidentes-de-trabalho-por-agentesquimicos/>. Acesso em: 28 de set. de 2018.

COPLE, Júlia. Desde 2000, intoxicação acidental por gás matou ao menos 532 pessoas no Brasil. oglobo.globo.com, 2019. Disponível em: <https://oglobo.globo.com/brasil/desde-2000-intoxicacao-acidentalpor-gas-matou-ao-menos-532-pessoas-no-brasil-23811253>. Acesso em 16 de jul. de 2019.

CORREIA, Arthur Horman. LIMA, Paul Yonggi. SANTOS, Tacio Vinicius. Sistema de proteção contra vazamento de gás inflamável e acúmulo de fumaça em ambientes fechados. Semana acadêmica. 2 de jan. de 2019. Disponível em <https://semanaacademica.org.br/system/files/artigos/sistema_de_protecao_contra_vazamento_de_gas_inflamav el_e_acumulo_de_fumaca_em_ambientes_fechados_0.pdf>. Acesso em 2 de jan. de 2019.

FERREIRA, Victor Ricardo. "Monóxido de carbono"; Brasil Escola. Disponível em: https://brasilescola.uol.com.br/quimica/monoxido-carbono.htm. Acesso em 30 de maio de 2020.

GIMENEZ, S. P. Microcontroladores 8051. 1ª ed. São Paulo: Pearson, 2005.

MARTINS, Danyely R. et al. Democratização da inovação tecnológica à luz da responsabilidade social: inserção de conceitos em prevenção de incêndios no arranjo físico do Centro de Madeira de Campina Grande. In: XXX ENCONTRO NACIONAL DE ENGENHARIA DE PRODUÇÃO. São Carlos, 2010. Disponível em: <http://www.abepro.org.br/biblioteca/enegep2010_tn_stp_123_794_16658.pdf>. Acesso em: 18 Nov. 2019.

O’MALLEY, Gerald F.; O’MALLEY, Rika. Intoxicação por monóxido de carbono. 2019. Disponível em: < https://www.msdmanuals.com/pt/casa/les\%C3\%B5es-eenvenenamentos/envenenamento/intoxica\%C3\%A7\%C3\%A3o-por-mon\%C3\%B3xido-de-carbono>. Acesso em: 30 maio. 2020.

SANTOS, D.M. RELÊ. Diego Marcelo dos Santos. Disponível em: <http://www.infoescola.com/eletronica/rele/> Acessado em: 18/11/2019.

SEITO, Alexandre I. (Coord.) et al. A segurança contra incêndio no Brasil. São Paulo: Projeto Editora, 2008. $496 \mathrm{p}$.

SILVEIRA, C.B. Sensor: Você sabe o que é quais os tipos? Cristiano Bertulucci Silveira, 2016. Disponível em: <https://www.citisystems.com.br/sensor-voce-sabe-que-quais-tipos/>Acessado em: 18/11/2019.

TORRES, Aline. Intoxicação por monóxido de carbono causou morte de família brasileira no Chile. uol.com.br, 2019. Disponível em: <https://noticias.uol.com.br/ultimas-noticias/agencia-estado/2019/06/01/intoxicacao-pormonoxido-de-carbono-causou-morte-de-familia-brasileira-no-chile.htm>. Acesso em 1 de jun. de 2019.

THOMSEN, A.T. O que é Arduino? Adilson Thomsen. Disponível em: <https://www.filipeflop.com/blog/oque-e-arduino/> Acessado em: 18/11/2019

XENIAX SOLUÇÕES EM TI. O que é um cooler e qual é a sua utilidade? Disponível em:

<http://www.eniax.com.br/novidades/o-que-e-um-cooler-e-qual-sua-utilidade/> Acessado em: 18/11/2019 